\title{
COMPARISON OF THE LEACHABILITY OF A SILICA-RICH QUARTZITE CONGLOMERATES CONTAINING A LAYER OF PYRITE USING CIP AND CIL
}

\author{
Michel Kalenga WA KALENGA, Joy NTULI \\ Department of metallurgy, School of mining, metallurgy and chemical engineering, Faculty of Engineering \\ and Built Environment, University of Johannesburg, Doornfontein, South Africa, michelk@uj.ac.za
}

https://doi.org/10.37904/metal.2020.3632

\begin{abstract}
South Africa is amongst the influential producers of gold worldwide. Many results have been published on its ores and different parameters defined. Although the carbon-in-pulp (CIP) and carbon-in-leach (CIL) have been largely investigated, optimum parameters change with the chemical composition of the ore based on the geological origins. The ore used in the present work was silica-rich quartzite conglomerates containing a layer of pyrite. The optimization of the gold recovery from the ore used and the better processing route between CIP and CIL were investigated and adopted. Alternating variations were conducted and most suitable leaching parameters were identified. Mineralogical test work conducted in the present investigation led to a better understanding of the ore mineralogy and assisted efficiently in resolving the reasons of impeding cyanidation with this ore. Also, the mineralogical results were compared with the ore, which is treated conventionally and identification of the problematic minerals was possible. XRD, XRF and AAS were used for characterization.
\end{abstract}

Keywords: Metallurgy, leachability, sulphide, gold concentrates

\section{INTRODUCTION}

The leachability of any ore depends on its chemical composition. It is well known that leaching a sulphide remains a challenge unless a pre-treatment conducted upstream. Researchers have used an oxidative ammoniacal solution as a pre-treatment to enhance the leaching of sulphides gold ore through the partial decomposition to expose the gold minerals to leaching [1]. Others have improved the leaching of a coppergold sulphide in ammonium thiosulphate medium by aerating the medium and adding the cupric ions [2]. It was attempted to replace the conventional roasting stage prior to leaching by leaching the refractory coppergold ore in a solution containing $0.8 \mathrm{M} \mathrm{S}_{2} \mathrm{O}_{3}{ }^{2-}, 0.05 \mathrm{M} \mathrm{Cu}^{2+}$ and $4 \mathrm{M} \mathrm{NH}_{3}$ [3]. During the leaching of a sulphide silver ore ferric-EDTA (ethylenediaminetetraacetic acid) complex was used as an alternative to the cupric ammonia catalysed thiosulfate system [4]. To the traditional thiosulfate solutions, sodium chloride, sodium sulphide, sodium carbonyl cellulose (CMC), sodium carbonyl starch (CMS) and humic acid sodium salt (HA) have been added to improve the leaching of a refractory gold ore [5]. Eh-pH diagrams for gold leaching in a Co- $\mathrm{NH}_{3}-\mathrm{S}_{2} \mathrm{O}_{3}{ }^{2-}-\mathrm{H}_{2} \mathrm{O}$ system through thermodynamic calculations were generated [6]. For years, cyanide has remained the most efficient and profitable method of dissolving gold from its host rocks since the late $19^{\text {th }}$ century. Cyanide can form highly stable dicyanoaurate ions, and the simplicity of cyanidation makes it favourable [7]. This work aimed at optimizing gold minerals leachability in order to decide on the best processing route between carbon-in-pulp and carbon-in-leach to yield higher recoveries for the silica-rich refractory gold ore and establish possible links between the mineralogy and its leachability.

\section{EXPERIMENTAL}

Samples from three different shafts were used namely shaft 1, 2 and Black reef. $\mathrm{HCl}$ and $\mathrm{HNO}_{3}$ were used to digest the head samples for characterization. X-Ray Diffraction (XRD) and X-Ray Fluorescence (XRF) were 
used as complementary analytical techniques for the characterization of the head samples whereas AAS (Atomic Absorption Spectroscopy) was used to analyse the solutions after leaching. Hydrogen peroxide was used as oxidizing agent while the leaching time varied from 24 to 48 hours. Two leaching techniques CIP and CIL were tested.

\section{RESULTS AND DISCUSSION}

Table 1 below presents the XRD results of the head sample.

Table 1 X-Ray fluorescence and head sample

\begin{tabular}{|c|c|c|c|}
\hline Elemental Analysis & Shaft 1 & Shaft 2 & Black Reef \\
\hline Grade $(\mathrm{g} / \mathrm{t} \mathrm{Au})$ & 5.662 & 5.139 & 4.82 \\
\hline Silica $(\mathrm{wt} \%)$ & 77.1 & 70.1 & 73.7 \\
\hline Iron (wt\%) & 10.6 & 14.9 & 6.26 \\
\hline Aluminum (wt\%) & 5.02 & 6.26 & 10.7 \\
\hline Potassium (wt\%) & 2.71 & 2.80 & 6.42 \\
\hline Sulphur (wt\%) & 1.57 & 1.50 & 0.84 \\
\hline Magnesium (wt\%) & 0.39 & 1.26 & 0.26 \\
\hline
\end{tabular}

The XRF analysis revealed that gold and silver were not in the detection range. The high percentages of Aluminum and potassium identified in black reef sample indicate the presence of preg-robbing constituents. For better accuracy diagnostic leaching was conducted in conjunction with this and other determinative analytical methods to draw better conclusions of the samples constituents.

Results of a qualitative analysis of XRD are presented in Figures 1, 2 and 3 below.

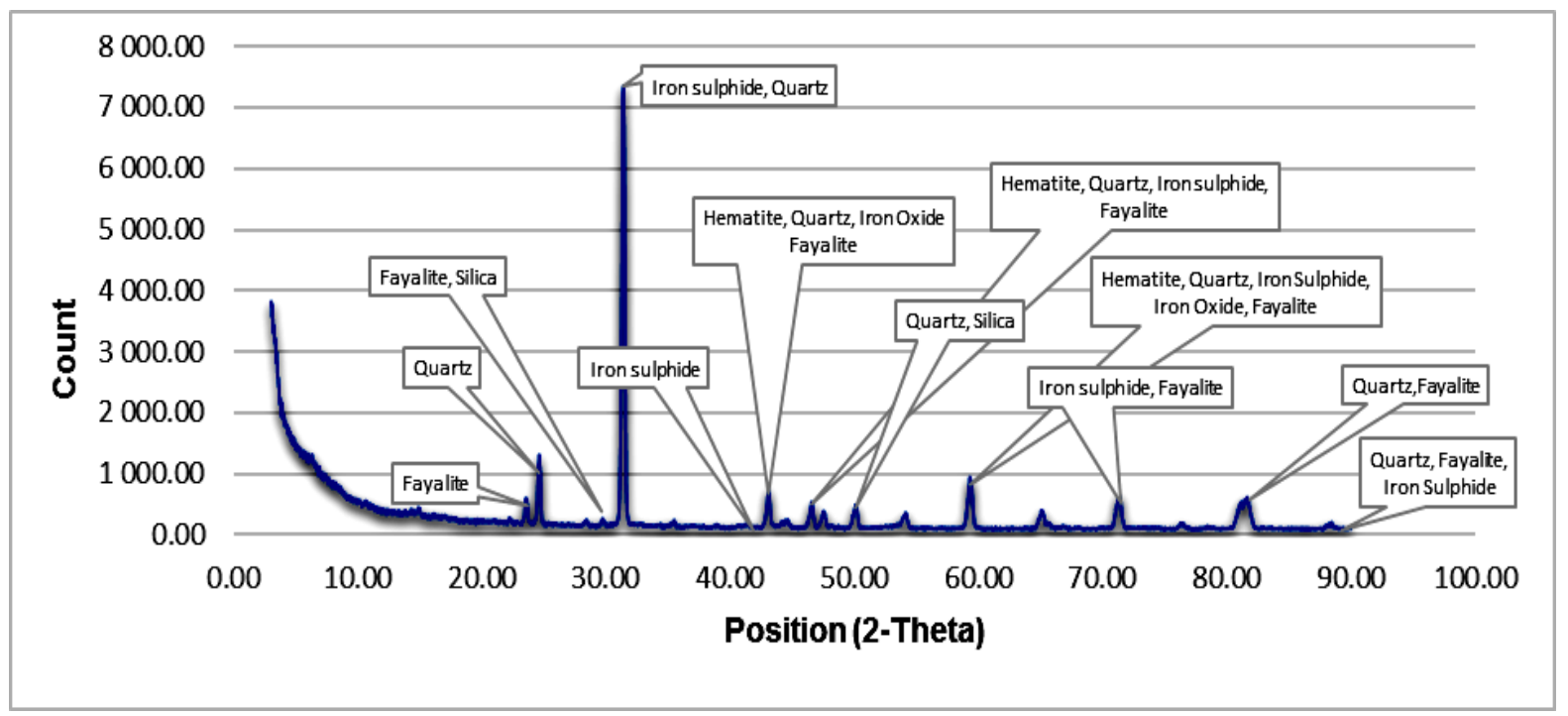

Figure $1 \mathrm{XRD}$ of the ore from shaft 1

From Figures 1 and $\mathbf{2}$ the major minerals in the 2 shaft sample, it is revealed that quartz, fayalite, iron sulphide, hematite and the presence of alumina in different phases are the major minerals depicted. The two shafts have rocks of similar mineralogical composition. It is, however noticed that the most abundant minerals are iron sulphide and quartz. 


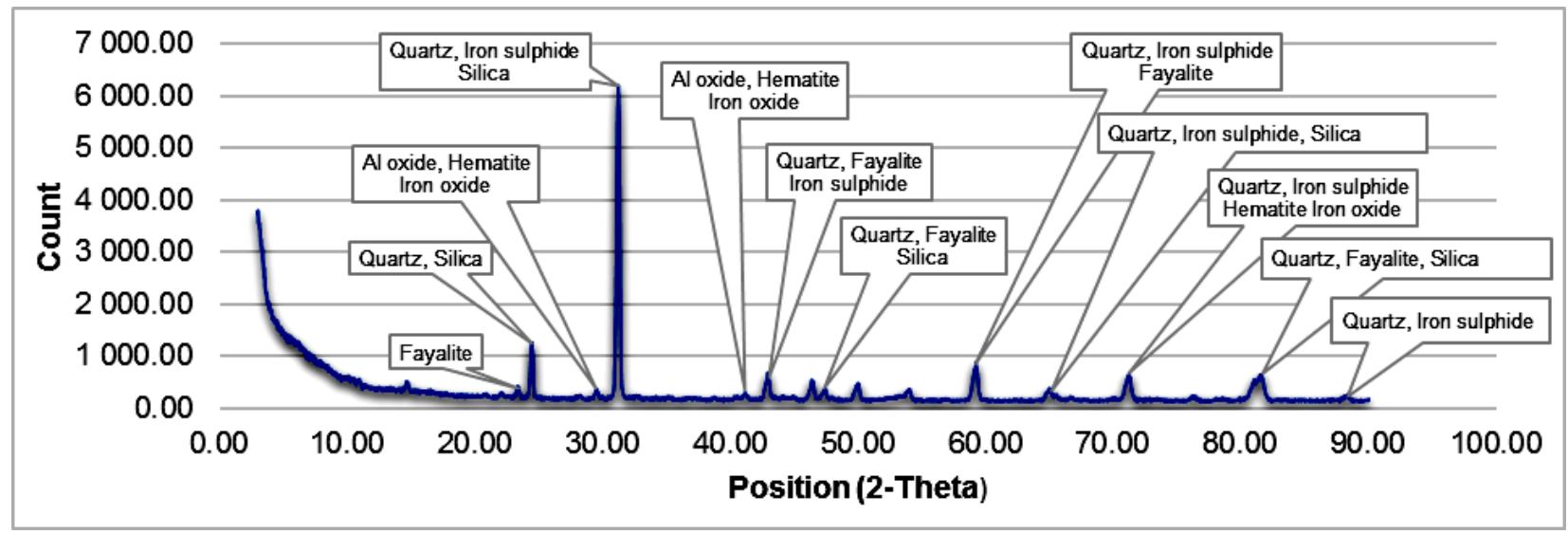

Figure $2 X R D$ of the ore from shaft 2

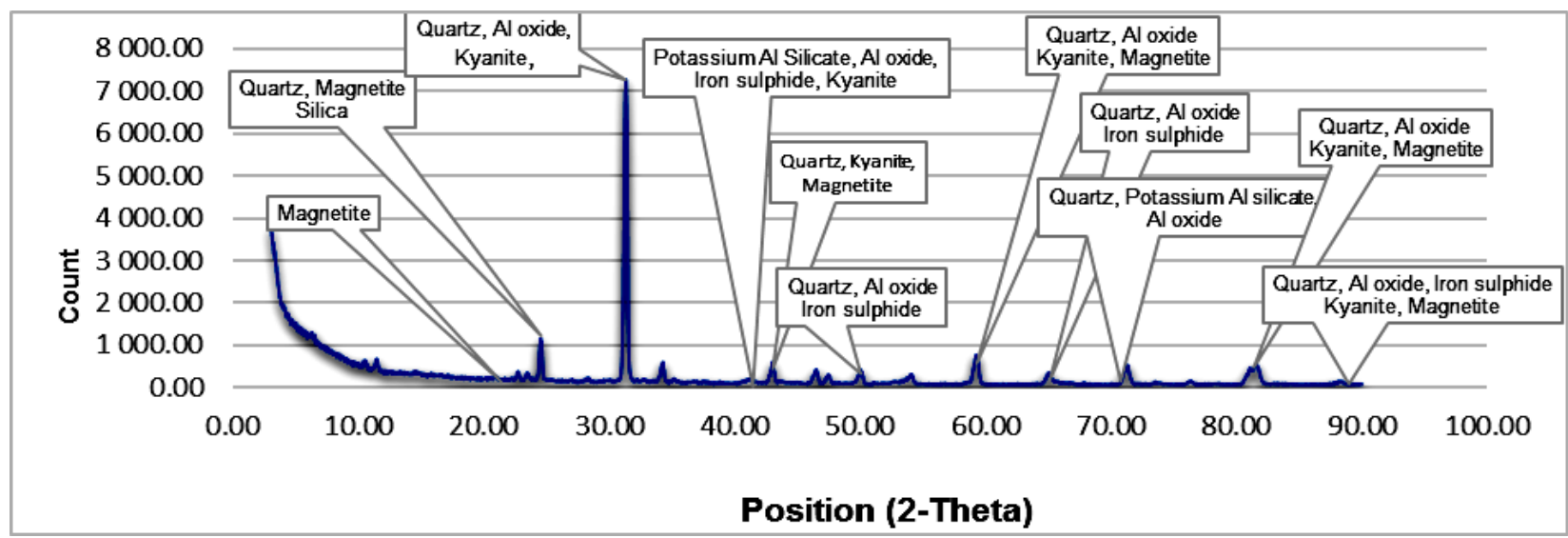

Figure 3 XRD of the ore from Black Reef

The major minerals identified in the black reef sample are quartz, iron sulphide, magnetite, potassium aluminum silicate, kyanite, magnetite and aluminum oxide present in differing phases.

It can be observed that although the samples used in the present investigation were from different shafts, they present similarities in their mineralogical composition. They are all siliciclastic and contain sulphides which make them difficult to leach.

\section{Diagnostic Leaching Results}

$9.49 \mathrm{~g}$ of the head grade sample was subjected to leaching using different processes for better diagnostic. The diagnostic leach chart presented in Figure 4 shows how the gold contained in the $9.49 \mathrm{~g}$ head grade sample behaved toward different dissolution processes and the corresponding wt $\%$ are reported. Of the total gold contained in the sample, $93.99 \mathrm{wt} \%$ was compliant to direct cyanidation. Under direct cyanidation conditions, 4.52 (wt\%) of the gold was preg-robbed within the sample, including $0.22 \mathrm{wt} \%$ of the carbonaceous material. In total, $98.29 \mathrm{wt} \%$ of the gold contained could be recoverable via carbon-in-leach processing. Of the remaining gold, $0.16 \mathrm{wt} \%$ was found to be associated with gangue components. For the shaft reef sample, the $\mathrm{HCl}$ digestion revealed that $1.0 \mathrm{wt} \%$ of the contained gold was associated with hydrochloric acid digestible minerals.

The nitric digestion phase showed that $0.33 \mathrm{wt} \%$ of the gold was associated with digestible nitric minerals such as pyrite and arsenopyrite. However, for the Black reef sample, the $\mathrm{HCl}$ digestion revealed that $3.35 \mathrm{wt} \%$ of the contained gold was associated with hydrochloric acid digestible minerals. The nitric digestion phase showed that $2.68 \mathrm{wt} \%$ of the gold was associated with digestible nitric minerals. 

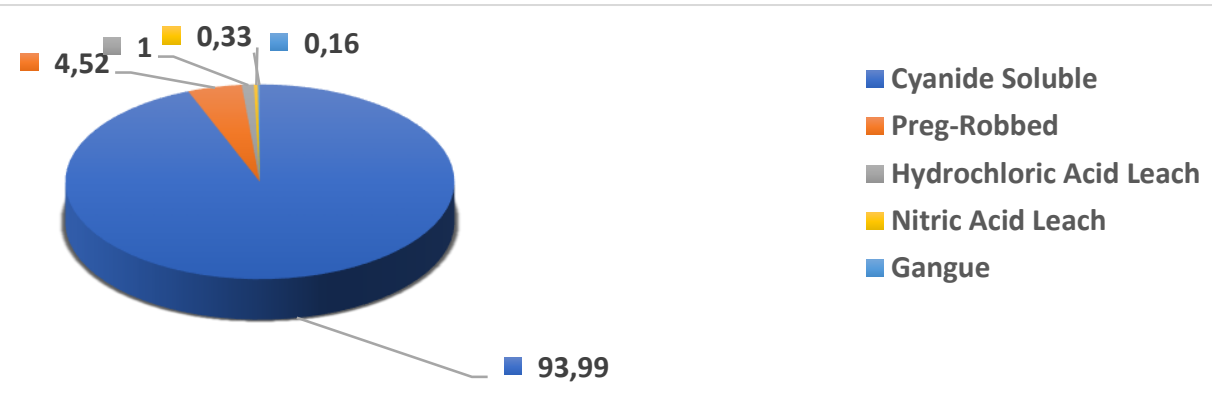

Figure 4 Gold (wt\%) dissolved by different dissolution processes (shaft sample)

Table 2 Gold association for shaft reef sample

\begin{tabular}{|c|c|c|c|c|}
\hline \multirow{3}{*}{ Gold Association } & \multicolumn{4}{|c|}{ Gold } \\
\hline & \multicolumn{2}{|c|}{$(g / t)$} & \multicolumn{2}{|c|}{$(w t \%)$} \\
\hline & Shaft reef & Black reef & Shaft reef & Black reef \\
\hline Direct Cyanidation & 8.915 & 2.014 & 93.99 & 46.52 \\
\hline Preg-Robbed CIL & 0.408 & 1.973 & 4.30 & 45.57 \\
\hline $\mathrm{HCl}$ digestible minerals & 0.095 & 0.145 & 1.00 & 3.35 \\
\hline $\mathrm{HNO}_{3}$ digestible minerals & 0.031 & 0.116 & 0.33 & 2.68 \\
\hline Carbonaceous materials & 0.021 & 0.031 & 0.22 & 0.71 \\
\hline Quartz & 0.015 & 0.051 & 0.16 & 1.17 \\
\hline Total & 9.485 & 4.33 & 100 & 100 \\
\hline Available Recovery via CIL & & & 98.29 & 92.09 \\
\hline
\end{tabular}

The diagnostic leach pie chart presented in Figure 5 below shows the available recovery using CIL. The head grade obtained from the black reef ore was assayed at $4.33 \mathrm{~g} / \mathrm{t}$. Only close to $47 \mathrm{wt} \%$ of total gold contained in the sample is amenable to direct cyanidation. The sample contained close to $46 \mathrm{wt} \%$ preg-robbing constituents, including carbonaceous materials. Of the remaining gold, $1.17 \mathrm{wt} \%$ was found to be associated with gangue components.

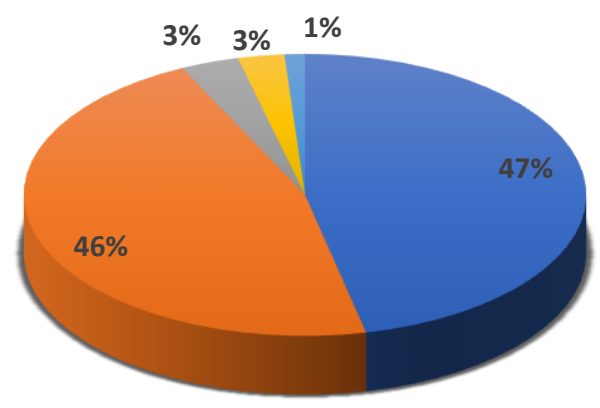

\author{
- Cyanide Soluable \\ - Preg-Robbed \\ Hydrochloric Acid Leach \\ Nitric Acid Leach \\ Gangue
}

Figure 5 Gold (wt\%) dissolved by different dissolution processes (black reef sample)

\title{
Leaching Results
}

Figure 6 shows the results for straight carbon-in-pulp leaching at different time intervals. Results revealed that the recovery of gold increased with increasing time, with the exception of 48 hours, at which the recovery 
dropped. This trend was presumably due to high presence of preg-robbing material as well as higher concentrations of other metals which when leached long enough possibly resorbed gold.

All of the tests shown in Figure 6 were conducted over a 24-hour period. In all of the CIL tests that were run, a carbon concentration of $20 \mathrm{~g} / \mathrm{l}$ was used.

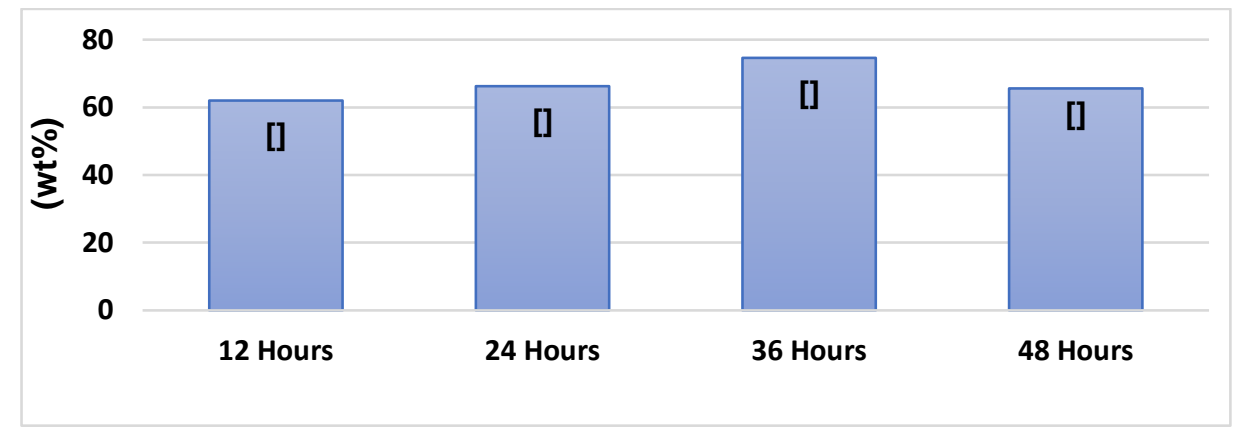

Figure 6 Recovery with different time intervals

The comparison of various leaching parameters between the CIP and CIL is presented in Table 3 below.

Table 3 Recovery with various leaching parameters using CIP and CIL

\begin{tabular}{|c|c|c|c|c|c|c|c|c|c|}
\hline \multicolumn{2}{|c|}{ Sample } & \multicolumn{2}{c|}{$\begin{array}{c}\text { Cyanide } \\
\text { concentration } \\
(\mathrm{ppm})\end{array}$} & \multicolumn{2}{c|}{$\mathrm{PbNO}_{3}(\mathrm{mg})$} & \multicolumn{2}{c|}{$\mathrm{H}_{2} \mathrm{O}_{2}(\mathrm{ml})$} & \multicolumn{2}{c|}{ Recovery (\%) } \\
\hline $\mathrm{CIP}$ & $\mathrm{CIL}$ & $\mathrm{CIP}$ & $\mathrm{CIL}$ & $\mathrm{CIP}$ & $\mathrm{CIL}$ & $\mathrm{CIP}$ & $\mathrm{CIL}$ & $\mathrm{CIP}$ & $\mathrm{CIL}$ \\
\hline $\mathrm{A}$ & $\mathrm{G}$ & 500 & 280 & - & - & - & - & 60.27 & 95.43 \\
\hline $\mathrm{B}$ & $\mathrm{H}$ & 1000 & 500 & - & - & - & - & 71.67 & 95.99 \\
\hline $\mathrm{C}$ & $\mathrm{I}$ & 280 & 1000 & 5 & 5 & - & - & 65.64 & 96.20 \\
\hline $\mathrm{D}$ & $\mathrm{J}$ & 280 & 280 & 10 & 10 & - & - & 68.17 & 96.35 \\
\hline $\mathrm{E}$ & $\mathrm{K}$ & 280 & 280 & - & - & 5 & - & 65.63 & 95.10 \\
\hline $\mathrm{F}$ & $\mathrm{L}$ & 280 & 280 & - & - & 10 & 5 & 68.16 & 94.40 \\
\hline & $\mathrm{M}$ & - & 280 & - & - & - & 10 & - & 96.35 \\
\hline
\end{tabular}

From Table 3, it can be seen with a cyanide concentration of $280 \mathrm{ppm}$ and no additional leaching enhancements, the average recovery attained from the CIP was $66.9 \%$ and $94.75 \%$ for the CIL. Further, the increase in cyanide concentrations from 500 to $1000 \mathrm{ppm}$ has led to an increase in recoveries. For CIP the recovery increased from $60.27 \%$ to $71.67 \%$ and from $95.99 \%$ to $96.20 \%$ for CIL. Furthermore, increasing cyanide concentration in both cases did not have the expected impact. However, unwanted minerals and elements may have played a role in cyanide consumption and got dissolved at higher concentrations of cyanide, creating a passivation layer on the gold surface.

With increasing hydrogen peroxide from $5 \mathrm{ml}$ to $10 \mathrm{ml}$, recoveries for the CIP and the CIL remarkably increased.

The comparison between CIP and CIL results is provided in Figure 7 below. The comparison between CIP and $\mathrm{CIL}$ of the bottle roll results are shown at different variations except bottle rolls leached at cyanide concentrations of 500 and 1000 ppm. Every other bottle roll test was run at $280 \mathrm{ppm}$ of cyanide. The addition of hydrogen peroxide as oxidizing agent during leaching has shown a positive effect on the minerology.

The last tests ran with the addition of lead nitrate at $5 \mathrm{mg}$ of $\mathrm{PbNO}_{3}$ and $10 \mathrm{mg} \mathrm{PbNO}_{3}$. With the batch that rolled with $5 \mathrm{mg}$ of lead nitrate the results for the CIP and the CIL were $65.64 \%$ and $94.40 \%$ respectively. 
With the batch that rolled with $10 \mathrm{mg}$ of lead nitrate, results for the CIP and CIL were $68.17 \%$ and $96.35 \%$ respectively. A slightly higher recovery is achieved with the CIL when lead nitrate is added. This is due to the lead nitrate passivating the pyrite by forming a hydroxide $\left(\mathrm{Pb}(\mathrm{OH})_{2}\right)$ layer on pyrite surface, reducing the dissolution of pyrite.
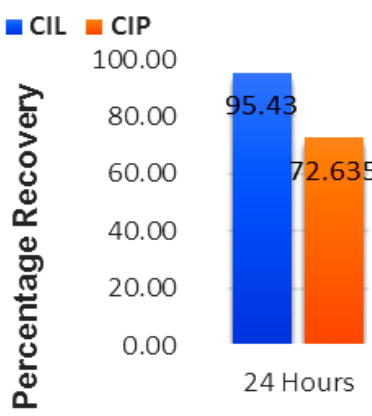

24 Hours

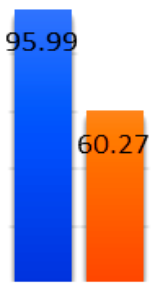

CN [] 500

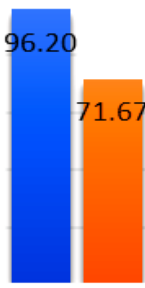

CN [] 1000

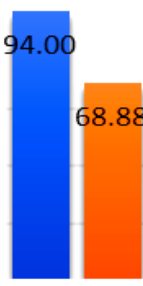

$\mathrm{H} 2 \mathrm{O} 25 \mathrm{ml}$

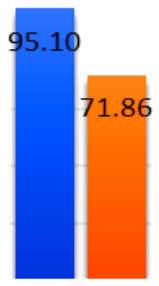

H2O2 10ml

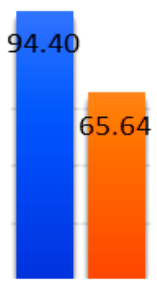

PbNO3 5mg

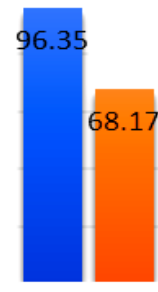

$\mathrm{PbNO}$ 10mg

Variations

Figure 7 Percentage Recovery obtained with CIL and CIP

\section{CONCLUSION}

Results have revealed that for the shaft reef sample, the $\mathrm{HCl}$ digestion showed that $1.0 \%$ of the contained gold was associated with hydrochloric acid digestible minerals whereas nitric digestion phase showed that $0.33 \%$ of the gold was associated with digestible nitric minerals such as pyrite and arsenopyrite. However, for the black reef sample, the $\mathrm{HCl}$ digestion revealed that $3.35 \%$ of the contained gold was associated with hydrochloric acid digestible minerals. The nitric digestion phase showed that $2.68 \%$ of the gold was associated with digestible nitric minerals. This showed that mineralogical test work conducted in the present investigation led to a better understanding of the ore mineralogy. Also, the comparison of the CIL and CIP results has shown that CIL had a recovery of $20 \%$ more than CIP. Therefore, it was found that for the treatment of the Black Reef ore CIL was best fit instead of conventional CIP.

\section{ACKNOWLEDGEMENTS}

The authors acknowledge the assistance of the technical team in the Department of Metallurgy, University of Johannesburg for their availability with analytical equipment.

\section{REFERENCES}

[1] FENG, D., VAN DEVENTER, J.S.J. Oxidative pre-treatment in thiosulphate leaching of sulphide gold ores. International Journal of Mineral Processing. 2010, vol. 94, no. 1-2, pp. 28-34.

[2] MOLLEMAN, E., DREISINGER, D. The treatment of copper-gold ores by ammonium thiosulphate leaching. Hydrometallurgy. 2002, vol. 66, no. 1-3, pp. 1-21.

[3] AYLMORE, M.G. Treatment of refractory gold-copper sulphide concentrate by copper ammoniacal thiosulfate leaching. Minerals Engineering. 2001, vol. 14, no. 6, pp. 615-637.

[4] DEUTSCH, J.L., DREISINGER, D.B. Silver leaching with thiosulfate in the presence of additives Part II: Ferric complexes and the application to silver sulphide ore. Hydrometallurgy. 2013, vol. 137, pp. 165-172.

[5] XU, B., YANG, Y., JIANG, T., LI,Q., ZHANG, X., WANG, D. Improved thiosulfate leaching of a refractory gold concentrate calcine with additives. Hydrometallurgy. 2015, vol. 152, pp. 214-222.

[6] LIU, X., XU, B., YANG, Y, LI, Q., JIANG, T, HE, Y. Thermodynamic analysis of ammoniacal thiosulphate leaching of gold catalysed by $\mathrm{Co}(\mathrm{III}) / \mathrm{Co}(\mathrm{II})$ using $\mathrm{Eh}-\mathrm{pH}$ and speciation diagrams. Hydrometallurgy. 2018, vol. 178, pp. 240-249.

[7] FLEMING, C.A. Hydrometallurgy of precious metals recovery. Hydrometallurgy. 1972, vol. 30, no. 1-3, pp.127-162. 